\title{
Corrigendum: Primary immunodeficiency diseases: an update on the classification from the International Union of Immunological Societies Expert Committee for Primary Immunodeficiency
}

\section{Waleed Al-Herz ${ }^{1,2}$, Aziz Bousfiha ${ }^{3}$, Jean-Laurent Casanova ${ }^{4,5}$, Talal Chatila ${ }^{6}$, Mary Ellen Conley $^{4}$, Charlotte Cunningham-Rundles ${ }^{7}$, Amos Etzioni ${ }^{8}$, Jose Luis Franco ${ }^{9}$, H. Bobby Gaspar ${ }^{10 *}$, Steven M. Holland ${ }^{11}$, Christoph Klein ${ }^{12}$, Shigeaki Nonoyama ${ }^{13}$, Hans D. Ochs ${ }^{14}$, Erik Oksenhendler ${ }^{15,16}$, Capucine Picard ${ }^{5,17}$, Jennifer M. Puck ${ }^{18}$, Kate Sullivan ${ }^{19}$ and Mimi L. K. Tang ${ }^{20,21,22}$}

1 Department of Pediatrics, Kuwait University, Kuwait City, Kuwait

${ }^{2}$ Allergy and Clinical Immunology Unit, Department of Pediatrics, Al-Sabah Hospital, Kuwait City, Kuwait

${ }^{3}$ Clinical Immunology Unit, Casablanca Children's Hospital, Ibn Rochd Medical School, King Hassan II University, Casablanca, Morocco

${ }^{4}$ St. Giles Laboratory of Human Genetics of Infectious Diseases, Rockefeller Branch, The Rockefeller University, New York, NY, USA

${ }^{5}$ Laboratory of Human Genetics of Infectious Diseases, Necker Branch, INSERM UMR1163, Imagine Institut, Necker Medical School, University Paris Descartes,

Paris, France

${ }^{6}$ Division of Immunology, Children's Hospital Boston, Boston, MA, USA

7 Department of Medicine and Pediatrics, Mount Sinai School of Medicine, New York, NY, USA

${ }^{8}$ Meyer Children's Hospital-Technion, Haifa, Israel

${ }^{9}$ Group of Primary Immunodeficiencies, University of Antioquia, Medellin, Colombia

${ }^{10}$ UCL Institute of Child Health, London, UK

$"$ Laboratory of Clinical Infectious Diseases, National Institute of Allergy and Infectious Diseases, Bethesda, MD, USA

12 Dr. von Hauner Children's Hospital, Ludwig-Maximilians-University Munich, Munich, Germany

${ }_{13}$ Department of Pediatrics, National Defense Medical College, Saitama, Japan

${ }_{14}$ Department of Pediatrics, Seattle Children's Research Institute, University of Washington, Seattle, WA, USA

${ }^{15}$ Department of Clinical Immunology, Hôpital Saint-Louis, Assistance Publique-Hôpitaux de Paris, Paris, France

${ }^{16}$ Sorbonne Paris Cité, Université Paris Diderot, Paris, France

${ }_{17}$ Centre d'étude des Déficits Immunitaires (CEDI), Hôpital Necker-Enfants Malades, AP-HP, Paris, France

${ }^{18}$ Department of Pediatrics, UCSF Benioff Children's Hospital, University of California San Francisco, San Francisco, CA, USA

${ }^{19}$ Division of Allergy Immunology, Department of Pediatrics, The Children's Hospital of Philadelphia, Philadelphia, PA, USA

${ }^{20}$ Murdoch Childrens Research Institute, Melbourne, VIC, Australia

${ }^{21}$ Department of Paediatrics, University of Melbourne, Melbourne, VIC, Australia

${ }^{22}$ Department of Allergy and Immunology, Royal Children's Hospital, Melbourne, VIC, Australia

${ }^{*}$ Correspondence: h.gaspar@ucl.ac.uk

Edited and reviewed by:

Jordan Orange, Baylor College of Medicine, USA

Keywords: immunodeficiency, classification, gene defects, genotype, IUIS

\section{A corrigendum on}

Primary immunodeficiency diseases: an update on the classification from the International Union of Immunological Societies Expert Committee for Primary Immunodeficiency

by Al-Herz W, Bousfiha A, Casanova JL, Chatila T, Conley ME, CunninghamRundles C, Etzioni A, Franco JL, Gaspar HB, Holland SM, Klein C, Nonoyama S, Ochs HD, Oksenhendler E, Picard C, Puck $J M$, Sullivan $K$ and Tang MLK. Front Immunol (2014) 5:162. doi:10.3389/fimmu. 2014.00162

In Table 1 of the original manuscript, two gene defects were inadvertently omitted.
These two defects (Cernunnos and DNA ligase IV deficiency) fall into the category of DNA recombination defects and lead to a radiosensitive form of SCID associated with microcephaly and developmental defects. These two genes have now been added to a revised Table 1.

Conflict of Interest Statement: The authors declare that the research was conducted in the absence of any commercial or financial relationships that could be construed as a potential conflict of interest.

Received: 03 September 2014; accepted: 09 September 2014; published online: 24 September 2014.

Citation: Al-Herz W, Bousfiha A, Casanova J-L, Chatila T, Conley ME, Cunningham-Rundles $C$, Etzion A, Franco JL, Gaspar HB, Holland SM, Klein C,
Nonoyama S, Ochs HD, Oksenhendler E, Picard C, Puck JM, Sullivan K and Tang MLK (2014) Corrigendum: Primary immunodeficiency diseases: an update on the classification from the International Union of Immunological Societies Expert Committee for Primary Immunodeficiency. Front. Immunol. 5:460. doi: 10.3389/fimmu.2014.00460

This article was submitted to Primary Immunodeficiencies, a section of the journal Frontiers in Immunology. Copyright (c) 2014 Al-Herz, Bousfiha, Casanova, Chatila, Conley, Cunningham-Rundles, Etzioni, Franco, Gaspar, Holland, Klein, Nonoyama, Ochs, Oksenhendler, Picard, Puck, Sullivan and Tang. This is an open-access article distributed under the terms of the Creative Commons Attribution License (CC BY). The use, distribution or reproduction in other forums is permitted, provided the original author(s) or licensor are credited and that the original publication in this journal is cited, in accordance with accepted academic practice. No use, distribution or reproduction is permitted which does not comply with these terms. 
Table 1 | Combined immunodeficiencies.

\begin{tabular}{|c|c|c|c|c|c|c|c|}
\hline Disease & $\begin{array}{l}\text { Genetic defect/ } \\
\text { presumed pathogenesis }\end{array}$ & Inheritance & $\begin{array}{l}\text { Circulating } \\
T \text { cells }\end{array}$ & $\begin{array}{l}\text { Circulating } \\
\text { B cells }\end{array}$ & Serum Ig & $\begin{array}{l}\text { Associated } \\
\text { features }\end{array}$ & $\begin{array}{l}\text { OMIM } \\
\text { number }\end{array}$ \\
\hline \multicolumn{8}{|c|}{ 1. $T^{-} B^{+}$Severe combined immunodeficiency (SCID) } \\
\hline (a) $\gamma c$ deficiency & $\begin{array}{l}\text { Mutation of IL2RG } \\
\text { Defect in } \gamma \text { chain of receptors } \\
\text { for IL-2, }-4,-7,-9,-15,-21\end{array}$ & $X L$ & Markedly decreased & $\begin{array}{l}\text { Normal or } \\
\text { increased }\end{array}$ & Decreased & $\begin{array}{l}\text { Markedly decreased } \\
\text { NK cells }\end{array}$ & 300400 \\
\hline $\begin{array}{l}\text { (b) JAK3 } \\
\text { deficiency }\end{array}$ & $\begin{array}{l}\text { Mutation of JAK3 } \\
\text { Defect in Janus activating } \\
\text { kinase } 3\end{array}$ & AR & Markedly decreased & $\begin{array}{l}\text { Normal or } \\
\text { increased }\end{array}$ & Decreased & $\begin{array}{l}\text { Markedly decreased } \\
\text { NK cells; }\end{array}$ & 600173 \\
\hline $\begin{array}{l}\text { (c) IL7R } \alpha \\
\text { deficiency }\end{array}$ & $\begin{array}{l}\text { Mutation of IL7RA } \\
\text { Defect in IL-7 receptor } \alpha \text { chain }\end{array}$ & AR & Markedly decreased & $\begin{array}{l}\text { Normal or } \\
\text { increased }\end{array}$ & Decreased & Normal NK cells & 146661 \\
\hline $\begin{array}{l}\text { (d) CD45 } \\
\text { deficiency }^{\text {a }}\end{array}$ & $\begin{array}{l}\text { Mutation of PTPRC } \\
\text { Defect in CD45 }\end{array}$ & AR & Markedly decreased & Normal & Decreased & Normal $\gamma / \delta T$ cells & 151460 \\
\hline $\begin{array}{l}\text { (e) } \operatorname{CD} 3 \delta \\
\text { deficiency }\end{array}$ & $\begin{array}{l}\text { Mutation of } C D 3 D \\
\text { Defect in } C D 3 \delta \text {, chain of } T \text { cell } \\
\text { antigen receptor complex }\end{array}$ & AR & Markedly decreased & Normal & Decreased & $\begin{array}{l}\text { Normal NK cells } \\
\text { No } \gamma / \delta T \text { cells }\end{array}$ & 186790 \\
\hline $\begin{array}{l}\text { (f) } \mathrm{CD} 3 \varepsilon \\
\text { deficiency }^{\mathrm{a}}\end{array}$ & $\begin{array}{l}\text { Mutation of } C D 3 E \\
\text { Defect in } C D 3 \varepsilon \text { chain of } T \text { cell } \\
\text { antigen receptor complex }\end{array}$ & $A R$ & Markedly decreased & Normal & Decreased & $\begin{array}{l}\text { Normal NK cells } \\
\text { No } \gamma / \delta \text { T cells }\end{array}$ & 186830 \\
\hline $\begin{array}{l}\text { (g) } \mathrm{CD} 3 \zeta \\
\text { deficiency }^{\mathrm{a}}\end{array}$ & $\begin{array}{l}\text { Mutation of } C D 3 Z \\
\text { Defect in } \mathrm{CD} 3 \zeta \text { chain of T-cell } \\
\text { antigen receptor complex }\end{array}$ & $A R$ & Markedly decreased & Normal & Decreased & $\begin{array}{l}\text { Normal NK cells } \\
\text { No } \gamma / \delta T \text { cells }\end{array}$ & 186740 \\
\hline $\begin{array}{l}\text { (h) Coronin-1A } \\
\text { deficiency }^{\mathrm{a}}\end{array}$ & $\begin{array}{l}\text { Mutation of CORO1A } \\
\text { Defective thymic egress of } \mathrm{T} \\
\text { cells and defective T cell } \\
\text { locomotion }\end{array}$ & $A R$ & Markedly decreased & Normal & Decreased & $\begin{array}{l}\text { Detectable thymus } \\
\text { EBV-associated B-cell } \\
\text { lymphoproliferation }\end{array}$ & 605000 \\
\hline \multicolumn{8}{|l|}{$\begin{array}{l}\text { 2. } T^{-} \mathrm{B}^{-} \text {SCID } \\
\text { (i) DNA recom }\end{array}$} \\
\hline $\begin{array}{l}\text { (a) RAG } 1 \\
\text { deficiency }\end{array}$ & $\begin{array}{l}\text { Mutation of } R A G 1 \\
\text { Defective VDJ recombination } \\
\text { Defect of recombinase } \\
\text { activating gene (RAG) } 1\end{array}$ & $A R$ & Markedly decreased & $\begin{array}{l}\text { Markedly } \\
\text { decreased }\end{array}$ & Decreased & & 601457 \\
\hline $\begin{array}{l}\text { (a) RAG } 2 \\
\text { deficiency }\end{array}$ & $\begin{array}{l}\text { Mutation of } R A G 2 \\
\text { Defective VDJ recombination; } \\
\text { defect of recombinase } \\
\text { activating gene (RAG) } 2\end{array}$ & $A R$ & Markedly decreased & $\begin{array}{l}\text { Markedly } \\
\text { decreased }\end{array}$ & Decreased & & 601457 \\
\hline $\begin{array}{l}\text { (b) DCLRE1C } \\
\text { (Artemis) } \\
\text { deficiency }\end{array}$ & $\begin{array}{l}\text { Mutation of ARTEMIS } \\
\text { Defective VDJ recombination; } \\
\text { defect in Artemis DNA } \\
\text { recombinase-repair protein }\end{array}$ & $A R$ & Markedly decreased & $\begin{array}{l}\text { Markedly } \\
\text { decreased }\end{array}$ & Decreased & Radiation sensitivity & 602450 \\
\hline $\begin{array}{l}\text { (c) DNA PKcs } \\
\text { deficiency }\end{array}$ & $\begin{array}{l}\text { Mutation of PRKDC } \\
\text { Defective VDJ recombination; } \\
\text { defect in DNA PKcs; } \\
\text { Recombinase repair protein }\end{array}$ & $A R$ & Markedly decreased & $\begin{array}{l}\text { Markedly } \\
\text { decreased }\end{array}$ & Decreased & $\begin{array}{l}\text { Radiation sensitivity, } \\
\text { microcephaly, and } \\
\text { developmental } \\
\text { defects }\end{array}$ & 600899 \\
\hline $\begin{array}{l}\text { d) Cernunnos/ } \\
\text { XLF deficiency }\end{array}$ & $\begin{array}{l}\text { Mutation of Cernunnos } \\
\text { Defective VDJ recombination; } \\
\text { defect in Cernunnos }\end{array}$ & $A R$ & Markedly decreased & $\begin{array}{l}\text { Markedly } \\
\text { decreased }\end{array}$ & Decreased & $\begin{array}{l}\text { Radiation sensitivity, } \\
\text { microcephaly, and } \\
\text { developmental } \\
\text { defects }\end{array}$ & 611291 \\
\hline
\end{tabular}


Table 1 | Continued

\begin{tabular}{|c|c|c|c|c|c|c|c|}
\hline Disease & $\begin{array}{l}\text { Genetic defect/ } \\
\text { presumed pathogenesis }\end{array}$ & Inheritance & $\begin{array}{l}\text { Circulating } \\
\text { T cells }\end{array}$ & $\begin{array}{l}\text { Circulating } \\
\text { B cells }\end{array}$ & Serum Ig & $\begin{array}{l}\text { Associated } \\
\text { features }\end{array}$ & $\begin{array}{l}\text { OMIM } \\
\text { number }\end{array}$ \\
\hline $\begin{array}{l}\text { e) DNA ligase } \\
\text { IV deficiency }\end{array}$ & $\begin{array}{l}\text { Mutation of LIG4 } \\
\text { Defective VDJ recombination; } \\
\text { defect in DNA ligase IV }\end{array}$ & AR & Markedly decreased & $\begin{array}{l}\text { Markedly } \\
\text { decreased }\end{array}$ & Decreased & $\begin{array}{l}\text { Radiation sensitivity, } \\
\text { microcephaly, and } \\
\text { developmental } \\
\text { defects }\end{array}$ & 601837 \\
\hline $\begin{array}{l}\text { (ii) Reticular } \\
\text { dysgenesis, }\end{array}$ & $\begin{array}{l}\text { Mutation of } A K 2 \\
\text { Defective maturation of }\end{array}$ & $A R$ & Markedly decreased & $\begin{array}{l}\text { Decreased or } \\
\text { normal }\end{array}$ & Decreased & $\begin{array}{l}\text { Granulocytopenia and } \\
\text { deafness }\end{array}$ & 103020 \\
\hline
\end{tabular}

$\begin{array}{ll}\text { AK2 deficiency } & \text { lymphoid and myeloid cells } \\ & \text { (stem cell defect) } \\ & \text { Defect in mitochondrial } \\ & \text { adenylate kinase } 2 .\end{array}$

$\begin{array}{ll}\text { (iii) Adenosine } & \text { Mutation of ADA } \\ \text { deaminase } & \text { Absent ADA activity, elevated } \\ \text { (ADA) } & \text { lymphotoxic metabolites } \\ \text { deficiency } & \text { (dATP, S-adenosyl } \\ & \text { homocysteine) }\end{array}$

AR

$\begin{array}{ll}\text { Absent from birth } & \text { Absent from } \\ \text { (null mutations) or } & \text { birth of } \\ \text { progressive } & \text { progressive } \\ \text { decrease } & \text { decrease }\end{array}$

Progressive

Decreased NK cells,

102700 decrease often with costochondral junction flaring, neurological features, hearing impairment, lung and liver manifestations; partial ADA deficiency may lead to delayed or milder presentation

\section{Combined immunodeficiencies generally less profound than severe combined immunodeficiency}

\begin{tabular}{|c|c|c|c|c|c|c|c|}
\hline $\begin{array}{l}\text { 3. CD40 ligand } \\
\text { deficiency }\end{array}$ & $\begin{array}{l}\text { Mutation of CD4OLG } \\
\text { Defects in CD40 ligand } \\
\text { (CD40L; also called TNFSF5 or } \\
\text { CD154) cause defective } \\
\text { isotype switching and } \\
\text { impaired dendritic cell } \\
\text { signaling }\end{array}$ & $X L$ & $\begin{array}{l}\text { Normal; may } \\
\text { progressively } \\
\text { decrease }\end{array}$ & $\begin{array}{l}\text { slgM+ and } \\
\text { slgD }{ }^{+} \text {B cells } \\
\text { present, other } \\
\text { surface isotype } \\
\text { positive B cells } \\
\text { absent }\end{array}$ & $\begin{array}{l}\text { lgM increased } \\
\text { or normal, } \\
\text { other isotypes } \\
\text { decreased }\end{array}$ & $\begin{array}{l}\text { Neutropenia, } \\
\text { thrombocytopenia; } \\
\text { hemolytic anemia, } \\
\text { biliary tract and liver } \\
\text { disease, opportunistic } \\
\text { infections }\end{array}$ & 300386 \\
\hline $\begin{array}{l}\text { 4. CD40 } \\
\text { deficiency }\end{array}$ & $\begin{array}{l}\text { Mutation of CD40 (also called } \\
\text { TNFRSF5); defects in CD40 } \\
\text { cause defective isotype } \\
\text { switching and impaired } \\
\text { dendritic cell signaling }\end{array}$ & AR & Normal & $\begin{array}{l}\operatorname{lgM}^{+} \text {and } \operatorname{lgD}^{+} \\
\text {B cells present, } \\
\text { other isotypes } \\
\text { absent }\end{array}$ & $\begin{array}{l}\text { lgM increased } \\
\text { or normal, } \\
\text { other isotypes } \\
\text { decreased }\end{array}$ & $\begin{array}{l}\text { Neutropenia, } \\
\text { gastrointestinal and } \\
\text { liver/biliary tract } \\
\text { disease, opportunistic } \\
\text { infections }\end{array}$ & 109535 \\
\hline $\begin{array}{l}\text { 5. Purine } \\
\text { nucleoside } \\
\text { phosphorylase } \\
\text { (PNP) } \\
\text { deficiency }\end{array}$ & $\begin{array}{l}\text { Mutation of PNP } \\
\text { Absent PNP, T cell and } \\
\text { neurologic defects from } \\
\text { elevated toxic metabolites, } \\
\text { especially dGTP }\end{array}$ & AR & $\begin{array}{l}\text { Progressive } \\
\text { decrease }\end{array}$ & Normal & $\begin{array}{l}\text { Normal or } \\
\text { decreased }\end{array}$ & $\begin{array}{l}\text { Autoimmune } \\
\text { hemolytic anemia, } \\
\text { neurological } \\
\text { impairment }\end{array}$ & 164050 \\
\hline $\begin{array}{l}\text { 6. CD3 } \gamma \\
\text { deficiency }\end{array}$ & $\begin{array}{l}\text { Mutation of } C D 3 G \\
\text { Defect in CD3 } \gamma \text {-component of } \\
\text { the } T \text { cell antigen receptor } \\
\text { complex }\end{array}$ & $A R$ & $\begin{array}{l}\text { Normal, but reduced } \\
\text { TCR expression }\end{array}$ & Normal & Normal & & 186740 \\
\hline $\begin{array}{l}\text { 7. CD8 } \\
\text { deficiency }\end{array}$ & $\begin{array}{l}\text { Mutation of CD8A } \\
\text { Defects of CD8 } \alpha \\
\text { chain - important for } \\
\text { maturation and function of } \\
\text { CD8T cells }\end{array}$ & $A R$ & $\begin{array}{l}\text { Absent CD8, normal } \\
\text { CD4 cells }\end{array}$ & Normal & Normal & & 186910 \\
\hline $\begin{array}{l}\text { 8. ZAP-70 } \\
\text { deficiency }\end{array}$ & $\begin{array}{l}\text { Mutation in ZAP70 } \\
\text { intracellular signaling kinase, } \\
\text { acts downstream of TCR }\end{array}$ & $A R$ & $\begin{array}{l}\text { Decreased CD8, } \\
\text { normal CD4 cells }\end{array}$ & Normal & Normal & $\begin{array}{l}\text { Autoimmunity in } \\
\text { some cases }\end{array}$ & 269840 \\
\hline
\end{tabular}


Table 1 | Continued

\begin{tabular}{|c|c|c|c|c|c|c|c|}
\hline Disease & $\begin{array}{l}\text { Genetic defect/ } \\
\text { presumed pathogenesis }\end{array}$ & Inheritance & $\begin{array}{l}\text { Circulating } \\
\text { T cells }\end{array}$ & $\begin{array}{l}\text { Circulating } \\
\text { B cells }\end{array}$ & Serum Ig & $\begin{array}{l}\text { Associated } \\
\text { features }\end{array}$ & $\begin{array}{l}\text { OMIM } \\
\text { number }\end{array}$ \\
\hline $\begin{array}{l}\text { 9. MHC class I } \\
\text { deficiency }\end{array}$ & $\begin{array}{l}\text { Mutations in TAP1, TAP2 or } \\
\text { TAPBP (tapasin) genes giving } \\
\text { MHC class I deficiency }\end{array}$ & $A R$ & $\begin{array}{l}\text { Decreased CD8, } \\
\text { normal CD4 }\end{array}$ & Normal & Normal & $\begin{array}{l}\text { Vasculitis; pyoderma } \\
\text { gangrenosum }\end{array}$ & 604571 \\
\hline $\begin{array}{l}\text { 10. MHC class } \\
\text { II deficiency }\end{array}$ & $\begin{array}{l}\text { Mutation in transcription } \\
\text { factors for MHC class II } \\
\text { proteins (CIITA, RFX5, RFXAP, } \\
\text { RFXANK genes) }\end{array}$ & $A R$ & $\begin{array}{l}\text { Normal number, } \\
\text { decreased CD4 cells }\end{array}$ & Normal & $\begin{array}{l}\text { Normal or } \\
\text { decreased }\end{array}$ & $\begin{array}{l}\text { Failure to thrive, } \\
\text { diarrhea, respiratory } \\
\text { tract infections } \\
\text { liver/biliary tract } \\
\text { disease }\end{array}$ & 209920 \\
\hline $\begin{array}{l}\text { 11. ITK } \\
\text { deficiency }\end{array}$ & $\begin{array}{l}\text { Mutations in ITK encoding IL-2 } \\
\text { inducible T cell kinase required } \\
\text { for TCR-mediated activation }\end{array}$ & $A R$ & $\begin{array}{l}\text { Progressive } \\
\text { decrease }\end{array}$ & Normal & $\begin{array}{l}\text { Normal or } \\
\text { decreased }\end{array}$ & $\begin{array}{l}\text { EBV associated B cell } \\
\text { lymphoproliferation, } \\
\text { lymphoma; normal or } \\
\text { decreased lgG }\end{array}$ & 613011 \\
\hline $\begin{array}{l}\text { 12. SH2D1A } \\
\text { deficiency } \\
\text { (XLP1) }\end{array}$ & $\begin{array}{l}\text { Mutations in } S H 2 D 1 A \\
\text { encoding an adaptor protein } \\
\text { regulating intracellular signals }\end{array}$ & $X L$ & $\begin{array}{l}\text { Normal or Increased } \\
\text { activated T cells }\end{array}$ & $\begin{array}{l}\text { Reduced } \\
\text { Memory B cells }\end{array}$ & $\begin{array}{l}\text { Partially } \\
\text { defective NK } \\
\text { cell and CTL } \\
\text { cytotoxic } \\
\text { activity }\end{array}$ & $\begin{array}{l}\text { Clinical and } \\
\text { immunologic features } \\
\text { triggered by EBV } \\
\text { infection: HLH, } \\
\text { Iymphoproliferation, } \\
\text { Aplastic anemia, } \\
\text { lymphoma; hypogam- } \\
\text { maglobulinemia, } \\
\text { absent iNKT cell }\end{array}$ & 308240 \\
\hline $\begin{array}{l}\text { 13. Cartilage } \\
\text { hair hypoplasia }\end{array}$ & $\begin{array}{l}\text { Mutations in RMRP (RNase } \\
\text { MRP RNA) Involved in } \\
\text { processing of mitochondrial } \\
\text { RNA and cell cycle control }\end{array}$ & $A R$ & $\begin{array}{l}\text { Varies from severely } \\
\text { decreased (SCID) to } \\
\text { normal; impaired } \\
\text { lymphocyte } \\
\text { proliferation }\end{array}$ & Normal & $\begin{array}{l}\text { Normal or } \\
\text { reduced. } \\
\text { Antibodies } \\
\text { variably } \\
\text { decreased }\end{array}$ & $\begin{array}{l}\text { Can present just as } \\
\text { combined } \\
\text { immunodeficiency } \\
\text { without other features } \\
\text { of short limbed } \\
\text { dwarfism, also see } \\
\text { Table } 2\end{array}$ & 250250 \\
\hline $\begin{array}{l}\text { 14. MAGT1 } \\
\text { deficiency }\end{array}$ & $\begin{array}{l}\text { Mutations in MAGT1, } \\
\text { impaired } \mathrm{Mg}^{++} \text {flux leading to } \\
\text { impaired TCR signaling }\end{array}$ & $X L$ & $\begin{array}{l}\text { Decreased CD4 cells } \\
\text { reduced numbers of } \\
\text { RTE, impaired T-cell } \\
\text { proliferation in } \\
\text { response to CD3 }\end{array}$ & Normal & Normal & $\begin{array}{l}\text { EBV infection, } \\
\text { lymphoma; viral } \\
\text { infections, respiratory, } \\
\text { and GI infections }\end{array}$ & 300715 \\
\hline $\begin{array}{l}\text { 15. DOCK8 } \\
\text { deficiency }\end{array}$ & $\begin{array}{l}\text { Mutations in } \\
\text { DOCK8 - regulator of } \\
\text { intracellular actin } \\
\text { reorganization }\end{array}$ & $A R$ & $\begin{array}{l}\text { Decreased Impaired } \\
\text { T lymphocyte } \\
\text { proliferation }\end{array}$ & $\begin{array}{l}\text { Decreased, low } \\
\text { CD27+ } \\
\text { memory B cells }\end{array}$ & $\begin{array}{l}\text { Low IgM, } \\
\text { increased lgE }\end{array}$ & $\begin{array}{l}\text { Low NK cells with } \\
\text { impaired function, } \\
\text { hypereosinophilia, } \\
\text { recurrent infections; } \\
\text { severe atopy, } \\
\text { extensive cutaneous } \\
\text { viral and bacterial } \\
\text { (staph.) infections, } \\
\text { susceptibility to } \\
\text { cancer }\end{array}$ & 243700 \\
\hline $\begin{array}{l}\text { 16. RhoH } \\
\text { Deficiency }\end{array}$ & $\begin{array}{l}\text { Mutations in } \mathrm{RHOH} \text { - an } \\
\text { atypical Rho GTPase } \\
\text { transducing signals } \\
\text { downstream of various } \\
\text { membrane receptors }\end{array}$ & $A R$ & $\begin{array}{l}\text { Normal low naïve } T \\
\text { cells and } \mathrm{RTE} \text {, } \\
\text { restricted } \mathrm{T} \text { cell } \\
\text { repertoire and } \\
\text { impaired } \mathrm{T} \text { cells } \\
\text { proliferation in } \\
\text { response to CD3 } \\
\text { stimulation }\end{array}$ & Normal & Normal & $\begin{array}{l}\text { HPV infection, } \\
\text { lymphoma, lung } \\
\text { granulomas, } \\
\text { molluscum } \\
\text { contagiosum }\end{array}$ & 602037 \\
\hline
\end{tabular}


Table 1 | Continued

\begin{tabular}{|c|c|c|c|c|c|c|c|}
\hline Disease & $\begin{array}{l}\text { Genetic defect/ } \\
\text { presumed pathogenesis }\end{array}$ & Inheritance & $\begin{array}{l}\text { Circulating } \\
\text { T cells }\end{array}$ & $\begin{array}{l}\text { Circulating } \\
\text { B cells }\end{array}$ & Serum Ig & $\begin{array}{l}\text { Associated } \\
\text { features }\end{array}$ & $\begin{array}{l}\text { OMIM } \\
\text { number }\end{array}$ \\
\hline $\begin{array}{l}\text { 17. MST1 } \\
\text { deficiency }\end{array}$ & $\begin{array}{l}\text { Mutations in STK4 - a } \\
\text { serine/threonine kinase }\end{array}$ & AR & $\begin{array}{l}\text { Decreased } \\
\text { increased proportion } \\
\text { of terminal } \\
\text { differentiated } \\
\text { effector memory } \\
\text { cells (TEMRA), low } \\
\text { naïve T cells, } \\
\text { restricted T cell } \\
\text { repertoire in the } \\
\text { TEMRA population } \\
\text { and impaired T cells } \\
\text { proliferation }\end{array}$ & Decreased & High & $\begin{array}{l}\text { Recurrent bacterial, } \\
\text { viral, and candidal } \\
\text { infections; intermittent } \\
\text { neutropenia; } \\
\text { EBV-driven } \\
\text { lymphoproliferation; } \\
\text { lymphoma; Congenital } \\
\text { heart disease, } \\
\text { autoimmune } \\
\text { cytopenias; HPV } \\
\text { infection }\end{array}$ & 614868 \\
\hline $\begin{array}{l}\text { 18. TCR } \alpha \\
\text { deficiency }\end{array}$ & $\begin{array}{l}\text { Mutations in TRAC - essential } \\
\text { component of the T cell } \\
\text { receptor }\end{array}$ & AR & $\begin{array}{l}\text { Normal All CD3 T } \\
\text { cells expressed } \\
\text { TCR } \gamma \delta \text { (or may be } \\
\text { better to say: TCR } \alpha \beta \\
\text { T-cell deficiency), } \\
\text { impaired T cells } \\
\text { proliferation }\end{array}$ & Normal & Normal & $\begin{array}{l}\text { Recurrent viral, } \\
\text { bacterial and fungal } \\
\text { infections, immune } \\
\text { dysregulation } \\
\text { autoimmunity, and } \\
\text { diarrhea. }\end{array}$ & 615387 \\
\hline $\begin{array}{l}\text { 19. LCK } \\
\text { deficiency }\end{array}$ & $\begin{array}{l}\text { Defects in } L C K \text { - a proximal } \\
\text { tyrosine kinase that interacts } \\
\text { with TCR }\end{array}$ & AR & $\begin{array}{l}\text { Normal total } \\
\text { numbers but CD4+ } \\
\text { T-cell lymphopenia, } \\
\text { low Treg numbers, } \\
\text { restricted T cell } \\
\text { repertoire and } \\
\text { impaired TCR } \\
\text { signaling }\end{array}$ & Normal & $\begin{array}{l}\text { Normal lgG } \\
\text { and } \lg \mathrm{A} \text { and } \\
\text { increased } \lg \mathrm{M}\end{array}$ & $\begin{array}{l}\text { Diarrhea, recurrent } \\
\text { infections, immune } \\
\text { dysregulation } \\
\text { autoimmunity }\end{array}$ & 153390 \\
\hline $\begin{array}{l}\text { 20. MALT1 } \\
\text { deficiency }^{\text {a }}\end{array}$ & $\begin{array}{l}\text { Mutations in MALT1 - a } \\
\text { caspase-like cysteine protease } \\
\text { that is essential for nuclear } \\
\text { factor-kappa-B activation }\end{array}$ & AR & $\begin{array}{l}\text { Normal impaired } \mathrm{T} \\
\text { cells proliferation }\end{array}$ & Normal & $\begin{array}{l}\text { Normal; } \\
\text { impaired } \\
\text { antibody } \\
\text { response }\end{array}$ & $\begin{array}{l}\text { Bacterial, fungal, and } \\
\text { viral infections }\end{array}$ & 604860 \\
\hline $\begin{array}{l}\text { 21. IL21R } \\
\text { deficiency }^{\mathrm{a}}\end{array}$ & $\begin{array}{l}\text { Defects in } I L 21 R \text { - together } \\
\text { with common gamma chain } \\
\text { binds IL-21 }\end{array}$ & $A R$ & $\begin{array}{l}\text { Abnormal T cell } \\
\text { cytokine production; } \\
\text { Abnormal T cell } \\
\text { proliferation to } \\
\text { specific stimuli }\end{array}$ & Normal & $\begin{array}{l}\text { Normal but } \\
\text { impaired } \\
\text { specific } \\
\text { responses }\end{array}$ & $\begin{array}{l}\text { Susceptibility to } \\
\text { cryptoporidia and } \\
\text { pneumocystis and } \\
\text { cholangitis }\end{array}$ & 605383 \\
\hline $\begin{array}{l}\text { 22. UNC119 } \\
\text { deficiency }^{\mathrm{a}}\end{array}$ & $\begin{array}{l}\text { Defects in UNC119 - an } \\
\text { activator of src tyrosine } \\
\text { kinases }\end{array}$ & $A D$ & $\begin{array}{l}\text { Low T cells; CD4+ } \\
\text { T-cell lymphopenia, } \\
\text { impaired TCR } \\
\text { signaling }\end{array}$ & Mostly low & Normal & $\begin{array}{l}\text { Recurrent bacterial, } \\
\text { fungal, and viral } \\
\text { infections }\end{array}$ & 604011 \\
\hline $\begin{array}{l}\text { 23. CARD11 } \\
\text { deficiency }^{a}\end{array}$ & $\begin{array}{l}\text { Defects in CARD } 11 \text { - acts as a } \\
\text { scaffold for NF-kB activity in } \\
\text { the adaptive immune } \\
\text { response }\end{array}$ & AR & $\begin{array}{l}\text { Normal } \\
\text { predominance of } \\
\text { naive T-lymphocyte, } \\
\text { impaired T cells } \\
\text { proliferation }\end{array}$ & $\begin{array}{l}\text { Normal } \\
\text { predominance } \\
\text { of transitional B } \\
\text { lymphocytes }\end{array}$ & Absent/low & $\begin{array}{l}\text { Pneumocystis jirovicii } \\
\text { pneumonia, bacterial } \\
\text { infections }\end{array}$ & 615206 \\
\hline $\begin{array}{l}\text { 24. OX40 } \\
\text { deficiency }^{\mathrm{a}}\end{array}$ & $\begin{array}{l}\text { Defects in } \mathrm{OX} 40 \text { - a co } \\
\text { stimulatory molecule } \\
\text { expressed on activated T cells }\end{array}$ & AR & $\begin{array}{l}\text { Normal T cell } \\
\text { numbers; low levels } \\
\text { of antigen specific } \\
\text { memory CD4+ cells }\end{array}$ & $\begin{array}{l}\text { Normal B cell } \\
\text { numbers; lower } \\
\text { frequency of } \\
\text { memory B cells }\end{array}$ & Normal & $\begin{array}{l}\text { Kaposi's sarcoma; } \\
\text { impaired immunity to } \\
\text { HHV8 }\end{array}$ & 615593 \\
\hline
\end{tabular}




\section{Table 1 | Continued}

\begin{tabular}{|c|c|c|c|c|c|c|c|}
\hline Disease & $\begin{array}{l}\text { Genetic defect/ } \\
\text { presumed pathogenesis }\end{array}$ & Inheritance & $\begin{array}{l}\text { Circulating } \\
\text { T cells }\end{array}$ & $\begin{array}{l}\text { Circulating } \\
\text { B cells }\end{array}$ & Serum Ig & $\begin{array}{l}\text { Associated } \\
\text { features }\end{array}$ & $\begin{array}{l}\text { OMIM } \\
\text { number }\end{array}$ \\
\hline $\begin{array}{l}\text { 25. IKBKB } \\
\text { deficiency }\end{array}$ & $\begin{array}{l}\text { Defects in IKBKB - encodes } \\
\text { IкB kinase } 2 \text {, a component of } \\
\text { the NF-кB pathway }\end{array}$ & AR & $\begin{array}{l}\text { Normal total T cells; } \\
\text { absent regulatory } \\
\text { and } \gamma \delta T \text { cells; } \\
\text { impaired TCR } \\
\text { activation }\end{array}$ & $\begin{array}{l}\text { Normal B cell } \\
\text { numbers; } \\
\text { impaired BCR } \\
\text { activation }\end{array}$ & Decreased & $\begin{array}{l}\text { Recurrent bacterial, } \\
\text { viral and fungal } \\
\text { infections; clinical } \\
\text { phenotype of SCID }\end{array}$ & 615592 \\
\hline $\begin{array}{l}\text { 26. Activated } \\
\text { PI3K- } \delta\end{array}$ & Mutation in $P I K 3 C D, P I 3 K-\delta$ & $\begin{array}{l}\text { AD gain of } \\
\text { function }\end{array}$ & $\begin{array}{l}\text { Decreased total } \\
\text { numbers of } \mathrm{T} \text { cells }\end{array}$ & $\begin{array}{l}\text { Decreased total } \\
\text { peripheral B cell } \\
\text { and switched } \\
\text { memory B } \\
\text { cells; increased } \\
\text { transitional B } \\
\text { cells }\end{array}$ & $\begin{array}{l}\text { Reduced IgG2 } \\
\text { and impaired } \\
\text { antibody to } \\
\text { pneumococci } \\
\text { and } \\
\text { hemophilus }\end{array}$ & $\begin{array}{l}\text { Respiratory infections, } \\
\text { bronchiectasis; } \\
\text { autoimmunity; chronic } \\
\text { EBV, and CMV } \\
\text { infection }\end{array}$ & 602839 \\
\hline $\begin{array}{l}\text { 27. LRBA } \\
\text { deficiency }\end{array}$ & $\begin{array}{l}\text { Mutations in } L R B A \\
\text { (lipopolysaccharide responsive } \\
\text { beige-like anchor protein) }\end{array}$ & $A R$ & $\begin{array}{l}\text { Normal or decreased } \\
\text { CD4 numbers; T cell } \\
\text { dysregulation }\end{array}$ & $\begin{array}{l}\text { Low or normal } \\
\text { numbers of B } \\
\text { cells }\end{array}$ & $\begin{array}{l}\text { Reduced I IgG } \\
\text { and IgA in } \\
\text { most }\end{array}$ & $\begin{array}{l}\text { Recurrent infections, } \\
\text { inflammatory bowel } \\
\text { disease, } \\
\text { autoimmunity; EBV } \\
\text { infections }\end{array}$ & 606453 \\
\hline $\begin{array}{l}\text { 28. CD27 } \\
\text { deficiency }\end{array}$ & $\begin{array}{l}\text { Mutations in CD27, encoding } \\
\text { TNF-R member superfamily } \\
\text { required for generation and } \\
\text { long-term maintenance of } T \\
\text { cell immunity }\end{array}$ & $A R$ & Normal & $\begin{array}{l}\text { No memory B } \\
\text { cells }\end{array}$ & $\begin{array}{l}\text { Hypogamma- } \\
\text { globulinemia } \\
\text { following EBV } \\
\text { infection }\end{array}$ & $\begin{array}{l}\text { Clinical and } \\
\text { immunologic features } \\
\text { triggered by EBV } \\
\text { infection, HLH; } \\
\text { aplastic anemia, } \\
\text { lymphoma, hypogam- } \\
\text { maglobulinemia, Low } \\
\text { iNKT cells }\end{array}$ & 615122 \\
\hline $\begin{array}{l}\text { 29. Omenn } \\
\text { syndrome }\end{array}$ & $\begin{array}{l}\text { Hypomorphic mutations in } \\
R A G 1, R A G 2 \text {, Artemis, IL7RA, } \\
R M R P, A D A, D N A \text { Ligase IV, } \\
\text { IL2RG, AK2, or associated } \\
\text { with DiGeorge syndrome; } \\
\text { some cases have no defined } \\
\text { gene mutation }\end{array}$ & & $\begin{array}{l}\text { Present; restricted } \mathrm{T} \\
\text { cell repertoire and } \\
\text { impaired function }\end{array}$ & $\begin{array}{l}\text { Normal or } \\
\text { decreased }\end{array}$ & $\begin{array}{l}\text { Decreased, } \\
\text { except } \\
\text { increased } \lg E\end{array}$ & $\begin{array}{l}\text { Erythroderma, } \\
\text { eosinophilia, } \\
\text { adenopathies, } \\
\text { hepatosplenomegaly }\end{array}$ & 603554 \\
\hline
\end{tabular}

$X L, X$-linked inheritance; $A R$, autosomal recessive inheritance; $A D$, autosomal dominant inheritance; SCID, severe combined immune deficiencies; EBV, Epstein-Barr virus; $\mathrm{Ca}^{++}$, calcium; MHC, major histocompatibility complex, RTE, recent thymic emigrants, HPV, human papillomavirus.

aTen or fewer unrelated cases reported in the literature.

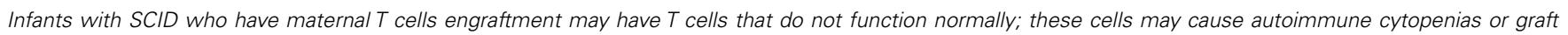

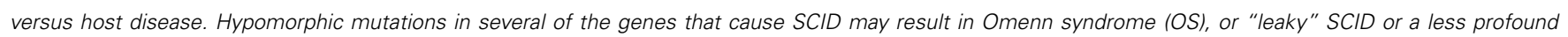

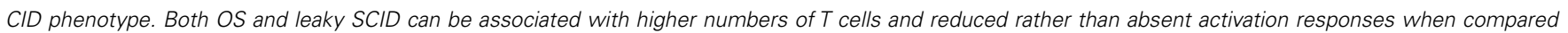
with typical SCID caused by null mutations. A spectrum of clinical findings including typical SCID, OS, leaky SCID, granulomas with T lymphopenia, autoimmunity, and CD4+ T lymphopenia can be found with RAG gene defects. RAC2 deficiency is a disorder of leukocyte motility and is reported in Table 5; however, one patient with RAC2 deficiency was found to have absent T cell receptor excision circles (TRECs) by newborn screening, but $T$ cell numbers and mitogen responses were not impaired. For additional syndromic conditions with T cell lymphopenia, such as DNA repair defects, cartilage hair hypoplasia, IKAROS deficiency, and NEMO syndrome,

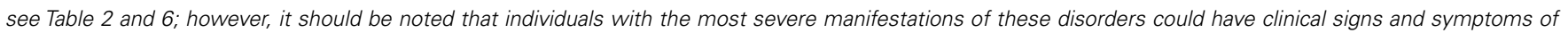
SCID. Severe folate deficiency (such as with malabsorption due to defects in folate carrier or transporter genes SLC10A1 or PCFT) and some metabolic disorders, such as methylmalonic aciduria, may present with reversible profound lymphopenia in addition to their characteristic presenting features. 